\section{Caso de ESTUDIO}

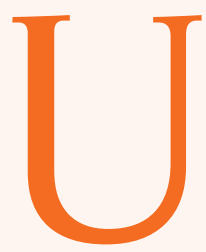

sted se encuentra laborando con un equipo interdisciplinario en un EBAIS, están trabajando con adolescentes y Ana, una adolescente de 14 años y 6 meses; quiere verse muy bella para sus quince años, está dispuesta a hacer lo que sea para entrar en un vestido talla 4 que la señora donde limpia su mamá le ofreció regalarle ya que no lo usa y a Ana le encanta.

Reside en Oreamuno y para llegar a su colegio debe caminar 45 minutos diarios de ida de y vuelta, vive con su mamá en la casa de una finca que cuidan sus abuelitos.

Para comer habitualmente hay arroz, frijoles, y cuando alcanza el dinero una vez por semana un pedacito de carne, la abuelita hace natilla y pan casero para vender y el abuelito además de cuida el ganado, la gallinas y cerdos siembra lechuga, tomate, culantro y zanahoria, los dueños les autorizan utilizar de estos productos para alimentarse.

Antropometría:

Peso: $58 \mathrm{Kg}$.

Talla: 155

P. tricipital: $13 \mathrm{~mm}=$ Normal

Circunferencia braquial: $25 \mathrm{cms}$

Cintura: 80 cintura cms / talla cms mayor 0,5

Sus exámenes bioquímicos indican los siguientes resultados:

Hemoglobina de $11,5 \mathrm{~g} / 100 \mathrm{ml}$ (normal 12,5 ) y un hematocrito de $34,8 \%$ (normal $37,3 \%)$

Colesterol total $180 \mathrm{mg} / \mathrm{dl}(170)$

Colesterol LDL 140 mg/dl (130)

Colesterol HDL 45 mg/dl (menos 40)

Triglicéridos $250 \mathrm{mg} / \mathrm{dl}$ (menos 200)

Presión arterial: 115/80
1. Esta joven se encuentra en la adolescencia o preadolescencia tardía.

2. Con la información recolectada haga un diagnóstico nutricional de la joven.

3. Calcule el RE de la joven.

4. Haga la distribución porcentual de macronutrientes del día.

5. Plantee el plan de alimentación con las listas de intercambio de PINEC, incluya el cálculo por cada grupo de alimentos, porcentajes de adecuación de macronutrientes y el ejemplo de menú.

6. Calcule la cantidad de calorías por tiempo de comida y porcentaje con respecto al VET.

7. El plan de alimentación propuesto cubre los nutrientes crítico: $\mathrm{Fe}, \mathrm{Ca}, \mathrm{Zn}$, folato, VIt A, E, C.

8. Bríndele la educación nutricional a la paciente.

9. Establezca metas nutricionales.

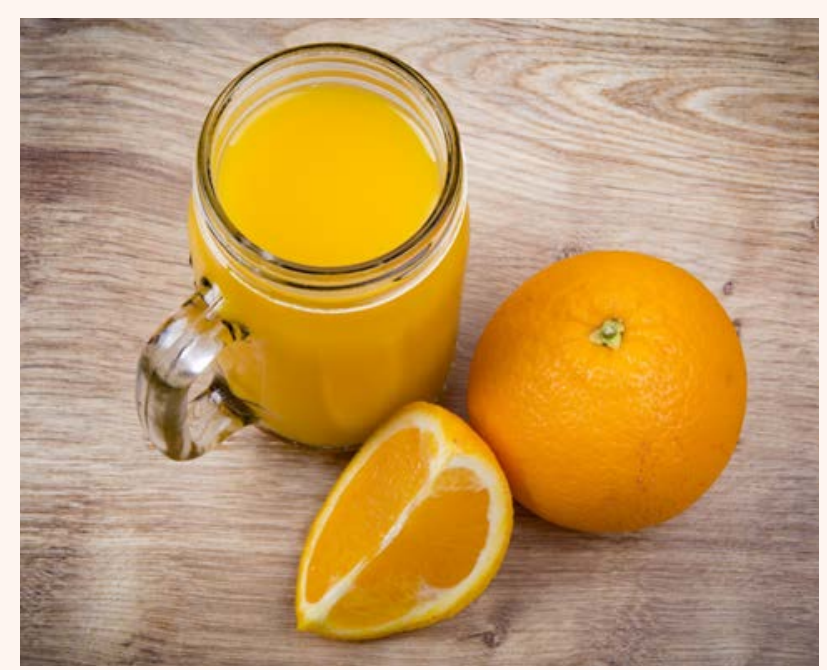

